\title{
Empirical Research on Usage Intentention and Behavior of "Toutiao" Users*
}

\author{
Ximing Li \\ Beijing Normal University, Zhuhai \\ Zhuhai, China 519087
}

\author{
Yi Zhang \\ Beijing Normal University, Zhuhai \\ Zhuhai, China 519087
}

\begin{abstract}
In recent years, the algorithm recommendation system has received attention and respect from the Internet industry. Today, as the representative platform of the algorithm recommendation technology news client, "Toutiao" has risen rapidly in the Internet information platform industry. Based on the technology acceptance model (TAM), this study incorporates the "cognitive entertainment" variables to reconstruct the theoretical models needed for this study. Through statistical analysis of the information obtained from the data research of "Toutiao" users, the purpose is to explore the factors influencing the intention of "Toutiao" users and to find the relationship between the intention of usage and the behavior of usage. Through research, it is found that the popularity of "Toutiao" is currently high among the people who use the new media information platform to obtain information in China, and there is a strong stickiness with users. From the perspectives of users' gender, age, education, etc., there are significant differences in intention and behavior of usage. The perceived usefulness has a significant correlation with intention of usage, and intention of usage has a significant influence on behavior of usage.
\end{abstract}

Keywords-algorithm recommendation; "Toutiao"; technology acceptance model; usage intention; usage behavior

\section{INTRODUCTION}

The birth and development of information technology has brought human civilization into a new chapter, making human society truly enter the information age. After decades of development, Internet technology has become increasingly mature and innovative. According to the 43rd Statistical Report on Internet Development in China (CNNIC), as of December 2018, the number of netizen in China reached 829 million, and the Internet penetration rate is $59.6 \%$. The number of mobile Internet users in China reached 871 million, and the size of online news users was 675 million. In this context, some new Internet technologies are constantly being created. The algorithm recommendation

*Fund: This paper is supported by 2018 characteristic innovation project of colleges and universities in Guangdong Province — "Research on the construction path of public opinion communication of Guangdong new think tank in the new media era" (No. 2018WTSCX195); 2018 Guangdong Higher Education and Teaching Reform Project — "Research on Practice Teaching Reform of Media Product Production Course under the Context of Media Integration" (Project No. 2018310); 2018 Moral Education Special Research Project of Guangdong Education Science of "13th Five-Year Plan" (No. 2018JKDY04); 2018 Research Capacity Improvement Project of Beijing Normal University, Zhuhai (No. 201105014). system is welcomed by the market and the industry as a new technology born along with the development of Internet technology. Its greatest advantage is the rapid screening and categorization of redundant information in a short period of time with the powerful computing power of the computer, thus reducing the burden of people's work (Zhang Yu, 2018).

In the aspect of algorithm recommendation technology, developed countries started earlier. The algorithm technology of information search and recommendation of companies such as Facebook, Amazon and Google is now maturing and leading in the world. The algorithm is a recommendation engine tool based on data mining. It uses algorithms to produce and publish news. It is obviously in an efficient state when compared with the traditional information publishing model, which makes related enterprises be in an advantageous position in the fierce market. As a large-scale publishing and sharing platform, "Toutiao" has become one of the fastest growing companies in the domestic mobile Internet industry through the introduction of this technology tool. Chen Lin (2018) said at the news conference, after 2015, "Toutiao" began to focus on the quality of content through the technology applications and strategy transformation, and proposed a plan of 1,000 headlines, which would provide a new platform for content creators. As of today, the number of monthly active users of "Toutiao" is close to 200 million.

Based on the current development status of "Toutiao", this study expects to understand the realities of usage intentions and usage behaviors of "Toutiao" users through research and data analysis. Through hypothesis verification, it can distinguish whether there are significant differences among different groups of multiple demographic variables in user's usage behavior; it can also study the inherent relationship among relevant factors that affect the user's willingness to use, usage intention and usage behavior. In the end, through data analysis, the author will feedback and think about the problems found in the research, and then interpret the communication significance of "Toutiao" from the user's point of view, and provide suggestions for the service and operation upgrade of "Toutiao".

\section{RESEARCH PROBLEM}

This research takes the users of "Toutiao" as the research objects and the technology acceptance model as the theoretical basis, and adopts the research method of 
quantitative analysis, and strives to explore the following questions through research:

First, this paper explores the usage intention and behavior of the users of news client using the algorithm recommendation technology represented by "Toutiao", understands the current user's cognition of the aggregate news client "Toutiao", and observes whether there is significant difference in the usage behavior among different groups of users grouped by demographic variables.

Second, this paper studies relevant factors that affect the users' usage intention, explores the relationship between usage intention and usage behavior, and verify whether there is a significant impact relationship.

Third, this paper uses the relevant theory of "use and satisfaction" of communication to interpret the behavior of "Toutiao" users, explore the communication significance and provide suggestions, making it provide better service to the audience.

\section{RESEARCH RESTRICTIONS}

Due to the limitations of the researcher's ability and professional background, this study does not cover the user's existence area to the greatest extent when conducting data research on "Toutiao" users. Therefore, there is a large gap between the total sample size of this study and the number of maternal subjects. At the same time, it is also because of the above reasons that the research failed to classify and sample the factors such as the occupational identity of "Toutiao" users as demographic variables. Therefore, the scientificity and representativeness of this study will be limited. The research results obtained are limited to the sample populations that have been sampled in this study, and the conclusions obtained cannot explain the characteristics of other unsampled populations.

\section{THEORETICAL BASIS OF RESEARCH}

The technology acceptance model (TAM) was developed by Davis based on theory of reasoned action (TRA). In the TAM model, Davis (1989) argues that the two influencing factors of perceived usefulness and perceived ease of use have an impact on people's intentions. In subsequent studies, Davis and his collaborators (2000) continued to enrich the TAM model and proposed the TAM2 model. In the TAM2 model, it is further pointed out that the usage behavior is determined by the usage intention, and the usage intention is

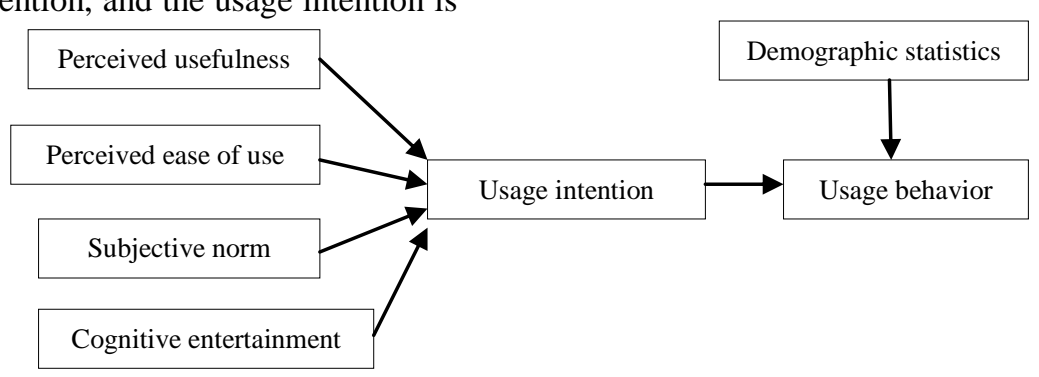

mainly influenced by three factors: perceived usefulness, perceived ease of use and subjective norm. "Toutiao" platform belongs to the aggregate news client, and as a media platform, it also takes into account the entertainment attributes of the media. At the same time, Davis proposed another factor influencing the usage intention of the information system in the subsequent research - cognitive entertainment. It believes that cognitive entertainment is the pleasure of people enjoying the use of products and services, and eliminates the benefits of using technology.

In the process of combing the literature, the researcher finds that in the research of algorithm recommendation, it involves a wide range of fields. Liu Cundi, Xu Wei (2018) believes that the algorithm cannot define society from the sociological level. Wang Xiyuan (2018) defined the algorithm as a "double-edged sword" in his research. He believed that how to use this double-edged sword required constant exploration. In this process, the mainstream media must firmly grasp the right to speak in their own hands. In the technical field, Shang Yanfei, Chen Deyun, Yang Hailu (2018) pointed out the shortcomings of several existing algorithm recommendation systems, and designed a mobile APP recommendation algorithm with better recommendation accuracy based on this research, satisfying users' demand. In other similar types of research, scholars are more likely to improve or innovate the field of "algorithm technology". For example, numerical experiments and comparative experiments show that the efficiency of improved algorithms is better than traditional collaborative filtering algorithms (Zhong Yao, Jiao Feng, Xiaoxi Chen, 2014).

\section{RESEARCH DESIGN}

\section{A. The Construction of Theoretical Models}

A new theoretical model based on the technology acceptance model (TAM2) is proposed in this study through combing the past literature and combining with the problems to be solved in this study, As shown in "Fig. 1", the new model reduces the dimensionality of the original TAM2 model, retaining the three influencing factors of "perceived usefulness", "perceived usability" and "subjective norm", and introduces a new influencing factor of "cognitive entertainment" to enrich and reshape the technology acceptance model (TAM2). Among the demographic variables, the author selects gender, age, and education as control variables to introduce the model.

Fig. 1. Theoretical model of this study. 


\section{B. The Presentation of Research Hypotheses}

The corresponding hypotheses are proposed separately combining with the problems to be solved in this study. Under the topic of "are there significant differences in usage behavior among "Toutiao" users with different demographic characteristics?", three corresponding hypotheses are established: H1: users of different genders do not have significant differences in usage behavior; $\mathrm{H} 2$ : users of different ages do not have significant differences in usage behavior; H3: users with different degrees of education do not have significant differences in usage behavior. Under the topic of "finding the relevant factors affecting the user's usage intention and observing whether the correlation is significant", four corresponding hypotheses are established: H4: perceived usefulness is not related to the users' usage intention; H5: perceived ease of use is not related to the users' usage intention; H6: subjective norms are not related to the users' usage intention; $\mathrm{H} 7$ : cognitive entertainment is not related to the users' usage intention. Under this research topic "exploring the relationship between the usage intention and the usage behavior and observing whether there is a significant impact", a corresponding hypothesis is established: H8: the users' usage intention has no significant effect on the usage behavior.

\section{Questionnaire Design}

In order to realize the research purpose of this research, the hypothesis proposed is verified in the subsequent quantitative analysis. In this study, three types of questions are set in the development of the scale. First, the demographic variables are used as control variables, and a total of three questions are set. Demographic variables are set according to their connotations, in which gender is set as a binary variable, age is set as a five-element variable, and education is set as a ternary variable. Second, difference is a factor variable. A total of 4 variables are set. This paper sets 6 questions to measure perceptual usefulness variable, sets 4 questions to measure the perceived ease of use variable, sets 4 questions to measure the subjective normative variable, and sets 3 questions to measure the cognitive entertainment variable. The study also adopts the Likert five-level scale, which is divided into five intensity measurements from strong disagreement to strong agreement. Third, it affects the relationship variable. Two variables are set. The usage intention is an independent variable, and it is convenient to set three questions to measure. The usage behavior is a dependent variable, and it is necessary to set three questions to measure. This paper uses the Likert five-level scale, which is divided into five intensity measurements from strong disagreement to strong agreement. In the scientific aspect of the scale, the questions set by the scale are from validated maturity scales, in which "perceived usefulness", "perceived ease of use", "usage behavior" and corresponding variables of demographic variables are cited from the mature scale of "empirical study on the usage intention and behavior of college students' mobile news client" of Fu Shiyao (2016), and the corresponding topics of "subjective norms", "cognitive entertainment", and "usage intentions" variable indicators are cited from the maturity scale of "usage behavior and intentions of WeChat users" of Wang Xiaoyu (2013).

\section{Questionnaire Distribution and Recycling}

Due to the researcher's research ability, this study uses data sampling in a convenient sampling manner. Relevant questionnaires were distributed on the web platform using electronic questionnaires. They were forwarded through WeChat group, circle of movements, QQ and fan groups of "Toutiao". The questionnaire collection period was 7 days, and 278 questionnaires were retrieved. The number of valid questionnaires was 252, and the effective rate of the questionnaire was $91.64 \%$.

\section{EMPIRICAL RESEARCH}

\section{A. The Reliability Test of Scale}

This study used the Cronbach's Alpha method to measure the reliability of the scale. As shown in "Table I", the overall reliability of the scale Cronbach's Alpha coefficient is 0.990; the Crowbach's Alpha coefficient of the "usage behavior" variable in the categorical variables is 0.748; and the Cronbach's Alpha reliability coefficient of the other variables are greater than 0.90 , indicating that the scale has higher reliability.

\section{TABLE I. S SUMMARY OF SCALE RELIABILITY}

\begin{tabular}{|l|l|l|}
\hline \multicolumn{1}{|c|}{ Variable } & Cronbach's alpha & $\begin{array}{c}\text { Number of } \\
\text { terms }\end{array}$ \\
\hline Perceived usefulness & 0.977 & 6 \\
\hline Perceived ease of use & 0.965 & 4 \\
\hline Subjective norm & 0.964 & 4 \\
\hline $\begin{array}{l}\text { Cognitive } \\
\text { entertainment }\end{array}$ & 0.947 & 3 \\
\hline Usage intention & 0.955 & 3 \\
\hline Usage behavior & 0.748 & 3 \\
\hline Overall reliability & 0.990 & 27 \\
\hline
\end{tabular}

\section{B. The Validity of Scale}

This study has made the scientific verification of the scale based on the constructive validity analysis. As shown in "Table II", factor analysis of various intensity variables such as perceived usefulness and perceived ease of use in this study was carried out. In the analysis, the KMO value of KMO test was 0.942, and Bartlett test value of Bartlett's sphericity test was 0.000 , less than 0.01 , indicating that the variable is suitable for factor analysis. And the scale has high constructive validity.

TABLE II. EXAMINATION OF KMO AND BARTLETT OF EACH INTENSITY VARIABLE IN THIS STUDY

\begin{tabular}{|c|c|l|}
\hline \multicolumn{2}{|c|}{$\begin{array}{c}\text { Measurement of KMO value of } \\
\text { sufficient sampling }\end{array}$} & .942 \\
\hline \multirow{3}{*}{$\begin{array}{c}\text { Bartlett's } \\
\text { sphericity test }\end{array}$} & $\begin{array}{c}\text { The approximate } \\
\text { chi-square }\end{array}$ & 2765.835 \\
\cline { 2 - 3 } & Df & 136 \\
\cline { 2 - 3 } & Sig. & .000 \\
\hline
\end{tabular}




\section{Demographic Description}

The researchers focused on the three demographic indicators of "gender", "age" and "education" related to the group being used. As shown in "Table III", at the gender level, men accounted for $50.4 \%$; women accounted for $49.6 \%$; and the number of men and women was more evenly distributed. At the age level, users concentrated on young and middle-aged groups aged 19-45, accounting for $82.9 \%$. Among them, the number of people aged 19 to 35 is the largest, accounting for $36.5 \%$ of the respondents. According to the "Statistical Report on the 43rd Internet Development of China" released by CNNIC, the netizens in China are mainly young and middle-aged groups. As of December 2018, the group aged 10 to 39 years old accounted for $67.8 \%$ of the total Internet users. The survey and statistical reports are also relatively close in value. At the academic level, the number of undergraduate (college) graduates is the highest, with a total of 135 , accounting for $53.6 \%$ of the survey. Secondly, the education background is junior high school, accounting for more than one-third of the number of people in this survey. The number of graduates or above is small, accounting for $13.5 \%$. It indicates that users who use "Toutiao" generally have a certain cultural literacy and a relatively high level of education.

TABLE III. SUMmary OF DEMOGRAPHIC Statistics OF THIS StUdy

\begin{tabular}{|l|l|l|l|l|}
\hline Characteristic variable & \multicolumn{1}{|c|}{ Type } & Number of people & Percentage (\%) & \multicolumn{1}{|c|}{ Cumulative percentage } \\
\hline \multirow{4}{*}{ Gender } & Male & 127 & $50.4 \%$ & $50.4 \%$ \\
\cline { 2 - 5 } & Female & 125 & $49.6 \%$ & $100 \%$ \\
\hline \multirow{5}{*}{ Age } & 18 years old or lower & 34 & 13.5 & 13.5 \\
\cline { 2 - 5 } & $19-25$ & 92 & 36.5 & 50.0 \\
\cline { 2 - 5 } & $26-35$ & 64 & 25.4 & 75.4 \\
\cline { 2 - 5 } & $36-45$ & 53 & 21.0 & 96.4 \\
\cline { 2 - 5 } & 45 or older & 9 & 3.6 & 100.0 \\
\hline \multirow{5}{*}{ Education background } & $\begin{array}{l}\text { Junior-senior high school (technical } \\
\text { secondary school) }\end{array}$ & 83 & 32.9 & 32.9 \\
\cline { 2 - 5 } & Undergraduate college (junior college) & 135 & 53.6 & 86.5 \\
\cline { 2 - 5 } & Postgraduate or higher & 34 & 13.5 & 100.0 \\
\hline
\end{tabular}

\section{Difference Testing}

It is convenient to verify the requirements of relevant hypotheses according to the requirements of this study, and the researchers performed an average difference test analysis on the relevant data.

\section{E. The Verification of the Difference Between Gender and Usage Behavior}

As shown in "Table IV", in the results of the independent sample $\mathrm{T}$ test of gender and usage behavior, the $\mathrm{t}$ value of the mean equation is 1.171 , lower than the corresponding significance level. The corresponding $\mathrm{P}$ value is 0.243 , greater than 0.05 . The null hypothesis is accepted, indicating that different gender users do not have significant differences in usage behavior. The hypothesis "H1: users of different genders do not have significant differences in usage behavior" is supported.

TABLE IV. Two INDEPENDENT SAMPLE T-TEST TABLES FOR GENDER AND USAGE BEHAVIOR

\begin{tabular}{|c|c|c|c|c|c|c|}
\hline & \multicolumn{2}{|c|}{$\begin{array}{c}\text { Levene test of variance } \\
\text { equation }\end{array}$} & \multicolumn{4}{|c|}{ The $t$ - test of mean equation } \\
\hline & $\boldsymbol{F}$ & 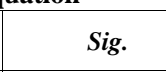 & $T$ & $D f$ & Sig.(double-side) & $\begin{array}{c}\text { The differences and } \\
\text { the average }\end{array}$ \\
\hline Equality & 3.710 & 055 & 1.171 & 250 & 243 & .08679 \\
\hline Behavior Non-equality & & & 1.169 & 244.399 & 243 & .08679 \\
\hline
\end{tabular}

\section{F. Verification of the Difference in Age and Usage} Behavior

As shown in "Table V", the $\mathrm{F}$ value in the one-way analysis of variance is 2.548 , which is higher than the corresponding significance level, and the corresponding $\mathrm{p}$ value is 0.040 , less than 0.05 . The null hypothesis is rejected, indicating that users of different ages have significant differences in using behaviors. The hypothesis "H2: users of different ages do not have significant differences in usage behavior" is not supported.

TABLE V. ONE-WAy ANALYSIS OF VARIANCE OF AGE AND UsAge BEHAVIOR

\begin{tabular}{|c|c|c|c|c|c|}
\hline \multirow{2}{*}{ Variable } & $\begin{array}{l}\text { Homogeneity test of } \\
\text { variance }\end{array}$ & \multicolumn{4}{|c|}{ One-way analysis of variance } \\
\hline & Levene statistic & Significance & Homogeneity & F & Sig value \\
\hline Usage behavior & .567 & .687 & Yes & 2.548 & .040 \\
\hline
\end{tabular}




\section{G. The Verification of the Difference Between Education Background and Usage Behavior}

As shown in "Table VI", the $\mathrm{F}$ value in the one-way analysis of variance is 0.129 , which is lower than the corresponding significance level, and the corresponding $\mathrm{P}$ value is 0.879 , which is greater than 0.05 . The null hypothesis is accepted, indicating that users with different education background do not have significant difference in usage behavior. The hypothesis "H3: users with different degrees of education do not have significant differences in usage behavior" is supported.

TABLE VI. ONE-WAY ANALYSIS OF VARIANCE OF EDUCATION BACKGROUND AND USAGE BEHAVIOR

\begin{tabular}{|c|c|c|c|c|c|}
\hline \multirow{2}{*}{ Variable } & $\begin{array}{c}\text { Homogeneity test of } \\
\text { variance }\end{array}$ & \multicolumn{4}{|c|}{ One-way analysis of variance } \\
\cline { 2 - 6 } & Levene statistic & Significance & Homogeneity & F & Sig value \\
\hline Usage Behavior & 1.436 & .240 & yes & .129 & .879 \\
\hline
\end{tabular}

\section{H. Relevance Analysis}

The study analyzes the correlation between perceived usefulness, perceived ease of use, subjective norms, cognitive entertainment, and usage behavior with usage intention respectively. As shown in "Table VII", the corresponding correlation coefficients are: 0.886, 0.799, $0.845,0.780$, and 0.489 . The corresponding significance level is less than 0.01 , and there was a significant correlation. The hypotheses such as "H4: perceived usefulness is not related to the users' usage intention"; "H5: perceived ease of use is not related to the users' usage intention"; "H6: subjective norms are not related to the users' usage intention"; "H7: cognitive entertainment is not related to the users' usage intention" are not supported.

TABLE VII. SUMMARY OF PEARSON CORRELATION COEFFICIENT ANALYSIS AMONG VARIABLES

\begin{tabular}{|l|l|}
\hline \multicolumn{1}{|c|}{ Variable } & Usage intention \\
\hline Perceived usefulness & $.866^{* *}$ \\
\hline Perceived ease of use & $.799 * *$ \\
\hline Subjective norm & $.845^{* *}$ \\
\hline $\begin{array}{l}\text { Cognitive } \\
\text { entertainment }\end{array}$ & $.780 * *$ \\
\hline Usage behavior & $.489 * *$ \\
\hline
\end{tabular}

a. **. There was a significant correlation at the.01 level (bilateral).

\section{Influence Relationship of Usage Intention on Usage Behavior}

As shown in "Table VIII", the R variance value is 0.996 in terms of model fit, indicating that the usage intention has a high degree of explanation for the usage behavior. As shown in "Table 9", the influence relationship coefficient of usage intention on usage behavior in the regression analysis is 0.669 , and the corresponding $\mathrm{t}$ value is 59.05 , which is greater than the corresponding significance level. The corresponding $\mathrm{P}$ value is 0.000 , less than 0.05 , indicating that usage intention has significant influence on usage behavior. The hypothesis "H8: users' usage intention has no significant effect on usage behavior" is not supported. According to the above regression analysis, the regression equation for the influence relationship of usage intention on usage behavior is established: usage behavior $=0.669 \times$ usage intention, ie: $\mathrm{Y}=0.669 \mathrm{x}$.
TABLE VIII. TEST OF GOODNESS OF FIT OF THE INFLUENCE RELATION OF USAGE INTENTION ON USAGE BEHAVIOR

\begin{tabular}{|c|l|l|l|}
\hline \multicolumn{1}{|c|}{$\mathbf{R}$} & \multicolumn{1}{|c|}{ R variance $^{\mathbf{b}}$} & Adjustment R variance $^{\text {Adjor of }}$ & $\begin{array}{c}\text { Error } \\
\text { standard } \\
\text { estimate }\end{array}$ \\
\hline $.966 \mathrm{a}$ & .933 & .933 & .64352 \\
\hline
\end{tabular}

TABLE IX. INFLUENCING COEFFICIENT TEST FOR INFLUENCE RELATIONSHIP OF USAGE INTENTION ON USAGE BEHAVIOR

\begin{tabular}{|c|c|c|c|c|c|}
\hline \multirow[t]{2}{*}{ Model } & \multicolumn{2}{|c|}{$\begin{array}{c}\text { Non-standardized } \\
\text { coefficient }\end{array}$} & \multirow{2}{*}{\begin{tabular}{|c|}
$\begin{array}{c}\text { Standard } \\
\text { coefficient }\end{array}$ \\
Trial version \\
\end{tabular}} & \multirow[t]{2}{*}{$\mathbf{T}$} & \multirow[t]{2}{*}{ Sig. } \\
\hline & $\mathrm{B}$ & Standard error & & & \\
\hline Usge intention & 669 & .011 & 966 & 59.050 & .000 \\
\hline \multicolumn{6}{|c|}{ a. Dependent variable: usage behavior } \\
\hline b Linear reores & ssion & ough the origin & & & \\
\hline
\end{tabular}

TABLE $X$. Hypothesis TEST CONCLUSION

\begin{tabular}{|l|l|l|}
\hline Number & \multicolumn{1}{|c|}{ Research hypothesis } & \multicolumn{1}{|c|}{$\begin{array}{c}\text { Validation } \\
\text { results }\end{array}$} \\
\hline H1 & $\begin{array}{l}\text { Users of different genders do not have } \\
\text { significant differences in usage behavior }\end{array}$ & Support \\
\hline H2 & $\begin{array}{l}\text { Users of different ages do not have } \\
\text { significant differences in usage behavior }\end{array}$ & Not support \\
\hline H3 & $\begin{array}{l}\text { Users with different degrees of education do } \\
\text { not have significant differences in usage } \\
\text { behavior }\end{array}$ & Support \\
\hline H4 & $\begin{array}{l}\text { Perceived usefulness is not related to the } \\
\text { users' usage intention }\end{array}$ & Not support \\
\hline H5 & $\begin{array}{l}\text { Perceived ease of use is not related to the } \\
\text { users' usage intention }\end{array}$ & Not support \\
\hline H6 & $\begin{array}{l}\text { Subjective norms are not related to the } \\
\text { users' usage intention }\end{array}$ & Unsupported \\
\hline H7 & $\begin{array}{l}\text { Cognitive entertainment is not related to the } \\
\text { users' usage intention }\end{array}$ & Not support \\
\hline H8 & $\begin{array}{l}\text { Users' usage intention has no significant } \\
\text { effect on usage behavior }\end{array}$ & Not support \\
\hline
\end{tabular}

The empirical study of the hypothesis test shows that H1 and $\mathrm{H} 3$ are both "supported", hypotheses such as H2, H4, H5, H6, H7, and H8 are "unsupported". From this, it can draw three conclusions. First, there is no significant difference in the gender and education background among the user groups of "Toutiao", and there are significant differences in the usage behaviors of user groups with different age. Second, there is a significant correlation among perceived usefulness, perceived ease of use, subject norms, cognitive entertainment, 
and the usage intention of the user community. Third, "Toutiao" users' usage behavior is significantly affected by their usage intention.

\section{CONCLUSION}

Based on the above three aspects of research conclusions, "Toutiao" should proceed in the following three aspects in the subsequent upgrade and deepening of products and services. The first is to think about the need for classification and recognition of user groups at the gender and academic level in terms of their layout and functional design and push logic. Instead, it is necessary to focus more on how to push and refine products and services according to age groups. Secondly, in order to increase the user stickiness of "Toutiao" user group to "Toutiao", and increase the frequency of user groups' access to information through "Toutiao" platform, and thus enable the platform to enhance profitability, "Toutiao" should start thinking about adjusting its functions, and the content has reached a resonance with consumers in terms of usefulness, ease of use, entertainment, and ethics, thereby enhancing the audience's usage intention. Finally, the usage behavior of the user groups of "Toutiao" has been seriously affected by the usage intention. Under the premise of enhancing their usage intentions and the foundation work of user stickiness, it believes that the frequency of usage behaviors of "Toutiao" users will further increase.

\section{REFERENCES}

[1] CNNIC: The 43rd Statistical Report on Internet Development in China [EB/OL], [2018-12]

[2] Zhang $\mathrm{Yu}$. The algorithmic turn of the aggregate news client [J]. Media Forum, 2018, 1 (17): 42-43. (in Chinese)

[3] Chen Lin. Toutiao announces an ecological upgrade and creates the most complete content platform for infrastructure [J]. China Commerce, 2018, 12 (11). (in Chinese)

[4] Fred D. Davis. Perceived usefulness, perceived ease of use, and user acceptance of information technology [J]. MIS Quarterly.1989

[5] Viswanath Venkatesh, Fred D.Davis. A Theoretical Extension of the Technology Acceptance Model:Four Longitudinal Field Studies [J]. Management Science. 2000 (2)

[6] Liu Cundi, Xu Wei. Can the Algorithm Define the Society - The News Algorithm Recommendation System from the Perspective of Media Sociology [J]. Academic Forum, 2018, 41(04): 28-37. (in Chinese)

[7] Wang Xiyuan. Research on content resources of aggregate news APP [D]. Beijing Institute of Graphic Communication, 2018. (in Chinese)

[8] Shang Yanfei, Chen Deyun, Yang Hailu. Personalized recommendation algorithm for mobile APP [J]. Journal of Harbin University of Science and Technology, 2018, 23(06):116-123. (in Chinese)

[9] Zhong Yao, Jiao Feng,Xiaoxi Chen.Collaborative filtering recommendation algorithms research based on influence and complex network [C]. IEEE Conferences, 2014,11.

[10] Wang Ning. Viewing personalized information recommendation" of the media from Toutiao [D]. Inner Mongolia Normal University, 2018. (in Chinese)

[11] Zhou Wenyang, Zhang Tianrong. Generation, Influence and Reflection: Research on the Information of the Aggregation News Client's Information: Taking the "Toutiao" as an Example [J]. Media, 2018(20): 94-96. (in Chinese) 